\title{
GCU
}

Glasgow Caledonian

University

University for the Common Good

\section{Back from the brink: ageing, exercise and health in a small gym}

Tulle, Emmanuelle; Dorrer, Nika

Published in:

Ageing and Society

DOI:

$10.1017 / \mathrm{S} 0144686 \mathrm{X} 11000742$

Publication date:

2012

Document Version

Author accepted manuscript

Link to publication in ResearchOnline

Citation for published version (Harvard):

Tulle, E \& Dorrer, N 2012, 'Back from the brink: ageing, exercise and health in a small gym', Ageing and Society, vol. 32, no. 7, pp. 1106-1127. https://doi.org/10.1017/S0144686X11000742

\section{General rights}

Copyright and moral rights for the publications made accessible in the public portal are retained by the authors and/or other copyright owners and it is a condition of accessing publications that users recognise and abide by the legal requirements associated with these rights.

Take down policy

If you believe that this document breaches copyright please view our takedown policy at https://edshare.gcu.ac.uk/id/eprint/5179 for details of how to contact us. 


\title{
Back from the brink: Ageing, exercise and health in a small gym EMMANUELLE TULLE AND NIKA DORRER \\ Glasgow Caledonian University \\ May 2011
}

Contact: Dr Emmanuelle Tulle, Dept of Social Sciences, Glasgow Caledonian University, Glasgow G4 0BA, e.tulle@gcu.ac.uk

Revised version to be published in Ageing and Society in early 2012

\begin{abstract}
This paper discusses data from a qualitative study which explored older adults' experiences of becoming regular exercisers in a gym triggered by health problems and their interactions with their younger gym instructors. A key question which the study sought to address was whether becoming embedded in the subfield of exercise challenged traditional discourses of ageing (age habitus). While these older gym users reported significant benefits they nevertheless were engaged in a complex and ambiguous negotiation of attitudes to bodily ageing and meanings of fitness and competence. Understandings of ageing as a process of biological decline, the budgetary constraints of the gym, and the more traditional models of exercise which the instructors drew on could create constraints on the older adults' pursuit of greater fitness. The paper suggests there is a need to develop ways of breaking down barriers in communication to overcome divergent understandings of what constitutes legitimate physical activity.
\end{abstract}

Keywords: old age, physical activity, sport, age habitus, health, gym

Introduction

This paper is based on a research project investigating understandings of ageing and exercise among older gym users and the younger instructors who support them. Apparently engaged in a common purpose of using exercise to promote and improve health, these two groups of people meet in exercise classes in an inner city gym specifically targeted at people who have survived CHD as well as anyone, symptomatic or otherwise, whose physical capital has been eroded over time. Arguably this is consistent with, and contributes to the consolidation of, a cultural shift which promotes exercise as first and foremost prescription for health, specifically for recovery from and prevention of diseases associated with ageing and poor lifestyle choices (Cress et al., 1999; Ferrara et al., 2002)(DeSouza, Stevenson, Davy, Parker Jones, \& Seals, 1997; 
Williamson \& Kirwan, 1997). This shift is most visible in the sport science literature and health promotion recommendations (e.g. ACSM 2010; WHO 2010). This begs a question regarding the status of bodily ageing and older people in contemporary Western society. Older people and their bodies have throughout the $20^{\text {th }}$ and early $21^{\text {st }}$ centuries experienced low status. The medicalisation of ageing has constructed a view of old age defined primarily by its physiological characteristics, from which the cultural status of older people has been derived. The turn to exercise opens the window to a future of improved physiological status. This potentially poses a challenge to the traditional discourse of ageing as a process of inevitable decline and concomitant cultural obsolescence. Our research suggests, however, that such dominant notions of ageing continue to impact on older people's experiences of exercising and their interaction with gym instructors in constraining ways.

The Reconstruction of Exercise as Prescription for Health As has now been well documented (Sassatelli, 2010), exercise and fitness have become ubiquitous in contemporary Western society. There has been a shift from centrally controlled forms of physical activity towards mass and yet highly individualised participation in physical activity based on hedonistic body work. Correspondingly, the places in which people learn and deploy physical competence (or what is constructed as such) have changed. The gym in particular is no longer the segregated and highly specialised space which it was until the 1970s (often highly masculine and working class). It is now much more open and fluid, apparently unsettling class, gender and race boundaries by encouraging diversity of provision.

The turn to physical activity and exercise cannot necessarily be confused with the trend towards hyper sporting achievement ever present in media reports of globalised sport competitions (see for instance Armstrong 2001 and 2004 as examples of literature which glorifies exceptional sporting physicality), although as we shall see later, the boundary between the two is not always impermeable. What is distinctive about the turn to mass exercise is the association of physical activity with health. There is now a substantial sport science literature, popularised in the media, showing apparent causal links between exercising and the prevention and even cure of the diseases prevalent in post industrial 
societies, and concomitant improvements in longevity (Asikainen, Kukkonen-Harjula, \& Miilunpalo, 2004; Beitz \& Doeren, 2004; Scottish Executive, 2005) Byberg et al., 2009; Shephard, 1997). So now we know that we should engage in specific forms of physical activity to protect ourselves from CHD, cancers, type II diabetes but also frailty. This is the next most distinctive and noteworthy aspect of the turn to physical activity: its extension to a group of people hitherto largely excluded from exercise as health promotion: the old, including the very old. Since the 1990s, sports science production has increased exponentially to demonstrate the value of physical activity in the later years and apparently transform traditional views about ageing bodies, from bodies of rest, incompetence and increasing immobility, to malleable bodies, prone to improved physiological and biomedical functioning (Author1 2008). As Author 1 has already shown, this transformation has been accomplished by giving scientific legitimacy to a key distinction: between normal and pathological ageing, reconstructed in biogerontology (the study of the biology of senescence) as primary and secondary ageing (Hunter, McCarthy, \& Bamman, 2004). Secondary ageing, usually understood as the decrements arising out of environmental and lifestyle factors, is open to intervention, by the prescription of tailored exercise regimens and lifestyle changes.

This has led to the emergence of and rapid expansion in a market in exercise and physical activity targeted at the old: step counters, gym balls, walking groups and gym classes. It has also led to the emergence of exercise professionals who specialise in working with older adults, the perception being that the latter have additional needs which preclude them attending 'mainstream' classes. Thus it is useful to conclude the discussion so far by highlighting the increasing role of exercise as prescription for health, dispensed by trained 'therapeutic recreation specialists' (see for instance Kunstler and Stavola Daly, 2010).

The ubiquity and expansion of exercise, the creation of safe and congenial spaces in which to perform it, the emergence of specialised instructors and the legitimacy lent to this trend mask an important obstacles: the continued reluctance of older people to engage in sustained and systematised physical activity and the apparent fear of gym or streets in which to act out exercise prescriptions. 
The literature tends to frame it as an information and understanding deficit (Balde, Figueras, Hawking, \& Miller, 2003; Nelson et al., 2007), that is as an age problem, rather than a cultural or discursive problem in which persistent stereotypes about ageappropriate behaviour and embodiment continue to clash with changing meanings of exercise. Furthermore as Tulle (2008) has shown elsewhere, engaging in sustained physical activity requires a commitment of time and re-adjustment of priorities which might be in conflict with family obligations and expectations of appropriate behaviour. Lastly, there is the issue of the body itself, its actual experience and sensations. The way we experience our bodies and deploy them is informed by deeply ingrained dispositions, mediated by our habitus (Bourdieu 1987), ie our social location. Body experiences are therefore highly social and cultural, but are felt as individual and personal. This tension between the personal and cultural will be illustrated in relation to the fear of overexertion.

Older adults have to develop a whole new language to interpret their bodies, now that they are encouraged to exercise in health promotion messages and policy interventions. Two types of questions emerge: Firstly what meanings do people who exercise for health attribute to exercise? The second question is prompted by the low cultural capital old people and old age enjoy in contemporary Western societies. Gullette (2004)) has shown how powerful the decline narrative which constructs older people as a burden and obsolete continues to be, how it is reinforced by policy initiatives which seek to reduce public expenditure related to the care of an increasing number of older people, correspondingly, the lack of positive messages about growing old and the (sometimes voluntary) relegation of the old to specialised spaces from which they rarely return.

\section{Theoretical and Conceptual Framework}

Theoretically and conceptually, the analysis and reflections presented here are informed by insights derived from the work of Pierre Bourdieu (1987), in particular his work on habitus, social field and sport. Bourdieu (1979) was concerned about the relationship between social action and wider structures such as class and status, to explain how people come to embody their class and status position. His analysis was structural, in that he focused mainly on the way structures are embodied and made manifest in people's 
strategies and actions, providing grids within which particular decisions are taken. Social action, according to Bourdieu, is geared towards distinction: our actions reflect or reproduce the amount of capital we have to bring to bear on our class or habitus position. The labour of distinction takes places in social fields, which act as microcosms of struggles for distinction. Sport is one such social field. Not only are different sporting disciplines - or sub-fields - imbued with class and status meaning. Within each, protagonists try hard to garner as much capital as is allowed within the sub-field. One distinctive feature of Bourdieu's work, and which will be reflected in the language used throughout this article, is his focus on the processes through which social actors come to embody their class position and engage in the struggle for distinction. His argument is that through socialisation processes, people internalise a range of dispositions which give them the propensity to act in particular ways, to have particular desires. This has two implications: 1. for Bourdieu, choices are partly pre-determined. Our class position, or habitus, and our encounter with a range of social fields equip us with the ability to make decisions which may seem improvised but are also structured. This process was referred to by Postone et al as ‘structured improvisation’. 2. Our habitus position is embodied and thus our physical appearance as well as how we deploy our bodies is indicative of our social location.

In previous work, Author 1 (2008) developed these insights further in work with Master runners. She showed that whilst the sporting field is permeated by values and beliefs prevalent in wider society, such as the association of ageing with inevitable decline, in the Masters running sub-field athletes can develop or maintain dispositions for sporting excellence late in life through intensive training. She demonstrated that this process of embodied transformation can act as a challenge to these beliefs in so far as the athletes are fully aware that they are engaged in this challenge. To this extent she argues that they are caught up in what she termed the 'age habitus', the internalisation of the undesirability of being old, because of the latter's association with decrepitude and obsolescence.

Therefore a key question remains whether body work of the kind encouraged by the sports science and health promotion literature signals a significant shift in the social and cultural position of older people within the sport and exercise sub-field. Does it mean a 
return of older adults to mainstream society and a corresponding challenge to the age habitus? The data which we will discuss below suggests the older gym users were indeed ambiguously positioned and constructed within this complex interplay between discourses, the physical experience of exercising and the everyday demands of running a sports centre. We will begin to illustrate these multi-layered meanings surrounding exercise for older adults by providing a description of the nature of the space within which the Active Senior classes were conducted. We will then focus on three themes which emerged from this analysis: 1 . Integration into the exercise sub-field, 2. Exercising as a way of managing physical capital and 3. ambiguous constructions of ageing.

\section{The Gym}

The research problem was operationalised in a study which took place in a university gym in Scotland. This gym has a mission of inclusiveness, in line with the University's own avowed mission. When it opened at its current premises in 1999 it received funding from the Lottery and from the Sports Council to develop a programme of community participation, encouraging non-traditional gym users to take up physical activity and feel comfortable about attending a gym. Subsequently the target groups which were identified became more diverse, consisting not only of academic staff and 'sporty' young students but also mature students, students from a range of ethnic and religious groups, as well as students from less affluent backgrounds. In addition staff actively promoted their classes and gym facilities within the local community. In order to create a non-threatening and accessible space for these diverse groups, staff at the gym introduced a number of policies and programmes which set it apart from more conventional university sports facilities. For example, the gym changed its name to something less sport-oriented. It adopted a dress code which forbids the wearing of revealing gym clothing such as cropped tops. To fulfil the objective of engaging and improving the health of the local community the gym set up a number of over 50s classes with the help of a consultant. In addition it took part in two wider health promotion schemes, the Live Active Exercise Referral Scheme (formerly known as the GP Exercise Referral Scheme) and the British Association of Cardiac Rehabilitation's (BACR) Phase IV scheme. For both schemes staff at the gym underwent extensive training to gain 
expertise in cardiac related issues, deliver the exercise program safely, carry out consultations, and motivate service users. A lot of effort was made to promote these classes to local physicians.

In the course of the first year of the scheme the gym received around 200 GP referrals and also ran a busy cardiac rehab class. Live Active classes were held three times weekly and users were offered gym membership at a reduced price, which led to many coming in at additional times to use the gym or join a medium level exercise class (Body Vive). During these initial years up to five members of staff were allocated to running the schemes and the gym invested a lot of time into consulting and monitoring referred users.

At the time of this research, ten years after the schemes were rolled out, the gym had shifted away from its focus on older users, largely due to budget cuts. Staff were no longer promoting the classes in the community and at GP surgeries, and referrals dropped from 200 to around 30 a year. Specialised staff who left were not replaced, and classes were reduced to three hours a week. With licences and BACR training for the cardio rehab scheme being costly, the cardio classes as well as Body Vive were stopped. Despite these changes, the gym continued to be successful in recruiting and retaining older members. Evaluations of the cardio rehabilitation scheme conducted elsewhere and the overall outcomes of the GP referral scheme have shown low retention rates (GGHB, 2000). The majority of patients do not maintain physical activity levels after completion of their phase III cardiac rehabilitation although exercise consultation has been found to have a positive effect on prolonged engagement (Hughes, Mutrie, \& MacIntyre, 2007). The gym compares very favourably to these outcomes with the majority of the older members who participated in this study having attended for many years and reporting positive effects far beyond their initial health concerns.

This provided an excellent environment in which to investigate the experiences of older adults who exercise regularly and of instructors, especially given the pressures for change which the gym were experiencing which provided a testbed for the effectiveness of exercise to unsettle the negative status attributed to old age. To this end, the research problem outlined earlier was operationalised along the following aims: 1. to chart how older adults use the gym, what exercise they undertake, how it affects their health and how it affects the meanings they attach to ageing embodiment; 2. to focus on instructors, 
more specifically how they make sense of their experiences of working with older adults, how they anticipate their own ageing and how they combine the health dimension of exercise with their own sporting aspirations.

Methods and Analysis

Given these objectives, we opted for a purposive sampling strategy. In the course of preparatory work we identified three populations of older users: people who attended what had once been GP referral and post-rehab classes and had been recast as Active Senior classes, a second group who attended for health reasons but confined themselves to the gym equipment and a third, much smaller, group consisting of Master athletes who used the gym to maintain or in one case develop athletic competence. We conducted interviews with 15 men and women aged 55-83. In this paper we will focus on the five women and two men who regularly attended the Active Senior Classes.

Among the staff, we recruited the three remaining instructors (two women and one man, aged 32-40) who had received specialist training and taught the Active Senior classes. In addition we conducted informal interviews with the Sport Centre director.

Data were collected from gym users in participant observation sessions and face-to-face life history interviews. With instructors we conducted short face-to-face life history interviews and one focus group session. We have used aliases throughout. For the purpose of this paper, the instructors' identity and gender have been concealed to ensure they cannot be recognised.

We attended Active Senior classes, as well as the weight rooms and most of the classes run by the Sport Centre, namely Body Pump, Spin, Circuit training and Body Attack, for participant observations. The sessions were designed to map out attendance (mix of young and old, male and female users), to observe social interactions between instructors and users but also among users as well as levels of commitment and to understand the structure of the class (for instance volume and type of music, how strenuous). The researchers had moderate levels of fitness at the start of the research which improved markedly by the end of the data collection period.

In life history interviews, we sought to explore with participants what role exercise and sport had played throughout their lives. Based on Author 1's (2008) work with Master 
elite runners, we focused on turning points and triggers for exercise, exercise regimes and how these had become embedded in everyday life, any barriers to exercise, including health problems and caring or work commitments, relationships with significant others and perceptions of personal ageing and bodily competence. We also asked participants to comment on exercise in later life as a policy goal.

With respect to instructors, we focused the life history interviews on establishing timelines for involvement in sport throughout the lifecourse and the transition to professional sport. We were also interested in the timing of appropriate training to work with older people. The focus group session was designed to explore how the instructors approached the classes and the social remit of the sport centre, whether their approach differed to that adopted for other classes and how they anticipated their own ageing. All the interviews were recorded on a digital recorder and uploaded to N-Vivo. We conducted the analysis in several stages. In Stage 1, we analysed each dataset separately. However we made some connections as follows: the participant observation sessions enabled the identification of potential users who could be approached for face-to-face interviews. Furthermore we used our observations to design the interview and focus group schedules. Whilst conforming to our ethical obligation of confidentiality and anonymity, we used the early findings from the instructor life history interviews to inform the focus group session.

In Stage 2, for each dataset, we sought to map timelines to understand individual biographies from the perspective of physical activity/exercise and look for overlaps and divergences. A typology of exercise participation emerged. We then identified a range of themes based on the substantive information provided by the research participants, which we compared across all the research participants.

In Stage 3, we moved the analysis towards the identification of potential narratives or cultural stories (Phoenix, Smith, \& Sparkes, 2010; Silverman, 2005) of embodied competence and ageing, focusing more specifically on the extent to which the informants' accounts reflected or challenged the traditional discourse of old age and ageing embodiment. We treated people's responses to our questions as articulation of experiences, feelings and sensations which reflected and helped construct wider cultural beliefs about bodily and ageing processes. In sum, our analysis sought to combine a 
socially constructed view of the world with the phenomenology of experience. We now turn to the presentation of findings.

Integration into the exercise sub-field

Although not noted athletes, the Active Seniors had not been entirely sedentary as younger adults. Walking, golf, dancing, home exercising, aerobics, in one case jogging and another badminton, had been performed regularly at one time or another. Therefore it is clear that the need or desire to be physically active had been present, although long term involvement had been hampered by time constraints or the belief that sport was not age-appropriate. The motivation to keep exercise going had also been a problem for one woman. What makes this group of informants distinctive is that illness - theirs or their friends' - had been the trigger for taking up exercise again in advanced age. Graeme states:

I didn’t really have much option. I had a triple bypass op and I was then more or less told that I would have to go to cardiac rehab class in the Royal Infirmary [...]. Well I did that for the 12 weeks and I was assessed and seemed to be getting on $\mathrm{OK}$ and they reckoned then I would be referred to a gym, just to carry on [...]. So by the time the [other] gym notified me, I had already decided to join here. [aged 75]

Some of these informants had been attending their classes for almost ten years. When we interviewed them they had successfully embedded exercise into their everyday lives. This was made manifest in two ways: by the encouragement of someone else and, particularly for women who lived on their own, by incorporating what they referred to as a 'social' element to their training. On being asked to comment on the place of exercising in her schedule, Sally makes the following connection:

So I would say it is quite a priority. Because it's simply the only thing I do that I call socialising a week bit, if you know what I mean [aged 67].

A similar comment is made by Rita who, on being asked why she keeps coming back to the class, weighs up different options as follows: 
I think there is (sic) two reasons. One is the health issue. Is that the important one? I think maybe not. I think maybe it's the enjoyment and the social aspect. [aged 71]

The social aspect of exercising - the companionship of exercising alongside and with others, but also the social activities that have spun off from meeting up once or twice a week at the sports centre - clearly provides the motivation for doing something that also has health benefits. The social is not incompatible with physical effort.

Indeed the informants expressed their commitment by using a work metaphor: they reported that whilst in the class they worked, they worked hard and they could feel this hard work. The class was a 'shift' and they took it very seriously. Some set targets and had a strategy (splitting the week or shift into different exercise sets to work or improve particular muscle groups). During a shift sweating was an indicator that one had worked very hard.

Agnes and Elizabeth (who were interviewed together at their own request and were 73 and 83 respectively) reported never sweating in the past but after a class felt moist at the back of the neck.

Agnes Sometimes you go out and you work really hard and it all depends what they have given you in that hour. Other times you go out and you feel 'I am fine’ you know 'I am not sweating' which I didn’t do anyway I must admit but I have started doing it now.

Elizabeth Aye me too, hair is usually soaking at the back.

Author 2 Is that a good thing or a bad thing?

Elizabeth Well they say it's a good thing you have been working hard. Norma (aged 69) reported the sense of satisfaction at performing competently, at overcoming a difficult routine:

Author 2 And what would be a good work out for you?

Norma Today was a good work-out. A good work-out is when it's hard and you can do it and you feel as if you have done well. That's a good work out.

So far we have shown that informants articulate their experiences using a language which reveals commitment and hard work. Bodily sensations such as sweating are used to put 
this message of hard work across. What they also articulate is a changed relationship to exercise and their bodies. Harry (aged 78) puts it this way:

And one of the things that I do feel is, if I don't come my body misses the exercise. And I didn’t think I would feel that way. But if I miss - say I miss the Friday- I feel I have missed out and I would need to go out walking or something to get my exercise. Because I feel better after I had my exercise.

What emerges is a specific modality of becoming integrated into the exercise sub-field, triggered by health concerns, with the social dimension of coming to the class facilitating motivation. Exercise comes to be perceived as work - it is therefore treated seriously and the transformation is completed by the incorporation of exercise, that is the felt need to be physically active, which indicates that the Active Seniors have internalised the disposition to exercise.

It is worth returning to the health dimension of exercise. Indeed these informants became embedded in the exercise sub-field because of health problems normally associated with ageing. Thus, exercise was used as a prescription for secondary ageing. What we would like to explore now is whether the positive effects of physical activity have led to a changed relationship to the informants' ageing bodies. Therefore we now turn to an examination of how informants perceive exercise in relation to their health and bodily capacities.

\section{Managing Physical Capital with Exercise}

Two Active Seniors had suffered life threatening health problems. Graeme but also Harry had suffered heart attacks. The women reported a range of conditions, such as osteoporosis or depression, or bodily changes which the classes were designed to address. Sally had significant mobility problems, the result of an industrial accident which had forced her to retire early, in her mid-50s. She became almost house-bound and developed angina. Since attending the gym, both her health and her mobility improved. She was now able to walk five miles to visit her cousin in hospital and:

[...] that's another thing as well, in the nine years that I have been coming here I think I used my spray twice. I wouldn’t say I ever use, you know the spray for 
angina, I wouldn't say I had to use it an awful lot anyway but about twice I would say. I can't even mind all that time, that I used my spray to be honest with you.

So I feel as though whether it's in my mind or so, but I feel it jolly helped me [...] Rita was one of the fittest and most ambitious in the group. She used to jog when she was in her 30s to keep fit and was keen to remain physically active. She acted as a 'motivator', that is she helped induct new class attenders to demystify the gym equipment and environment, facilitating the development of what we might call an exercise career among these new users. Rita's health was good and she attributed this to her regular exercise routine. However recently weight gain and breathlessness had hampered her fitness and she felt she was losing physical capital, something that we observed in participant observation sessions.

The issue of breathlessness came up regularly among the informants. Some informants, such as Isla, who was aged 62, experienced breathlessness as a loss of fitness which exercise could remedy. For others it was an indicator of ageing, rather than a normal manifestation of aerobic activity, and a signal to exercise caution:

Graeme Well the thing is that having an instructor there telling you what you are doing not ordering you but telling you what to do gives you the motivation to do that exercise and you know the thing yourself that exercise is doing you some good. I mean it's keeping the heart going and that's why we are here. [...] Sometimes you feel that they are making you work over hard. You know especially on these machines that are giving you a heart rate. I have got a very slow heart rate, well at rest it's normally only 55-60 and when I see these machines showing me sometimes 85 or 89 or 90 I think 'am I putting in too much effort here?'.

Author 2 You think you might be doing yourself some damage?

Graeme Well I do believe that you can overwork as well as not work at all. [Our emphasis]

In this quote, Graeme defies the instructors' recommendation to work harder and seeks justification for his belief that his heart rate can be dangerously elevated in the heart rate monitor. He does not provide any other evidence for this fear of over-exertion as there is no indication that his health has suffered from deploying maximal aerobic effort. 
What we have shown here is that exercise, triggered by a range of significant health problems, has proven beneficial: people feel healthy, they have regained lost mobility, in some cases most spectacularly, they have arrested severe illness. Thus they appear to have acquired as well as recovered physical capital. However this is tempered by anxiety about the limits of what their bodies can achieved, manifested in the fear of over-exertion which they see as a risk inherent to their bodies. This links in interesting ways with their status as old people, their understanding of what old age is and how it affects their lives. But it also stands in contradiction to the instructors' understandings of the bodily potential and capacity of older people and exercise. Therefore in the next section we explore the complex and ambiguous attitudes to bodily ageing and to this end we will also introduce the views of the instructors.

\section{Ambiguous Constructions of Ageing}

As we saw in the previous section, the older adults expressed an awareness of their physical limitations (whether corporeal or imagined) and they put boundaries on how much exertion they agree to subject themselves to. This makes the presentation of their ideas about their own old age all the more tantalising. On the one hand they claim not to be old, being old being understood first and foremost as attitudinal:

Author 2 Could I ask you how you would describe yourself in terms of age? Are you old?

Harry No. I am not feeling old. No. I feel, I want to feel as young as I can feel for as long as I can. And I feel, I just do, young - I feel there are things I can't do because I am old but I don't feel old, I try to feel young. [our emphasis] Harry talks about his age identity apparently using a language of sensations (I feel young, I don't feel old), a recurrent and well-worn phrase used almost universally by research participants who are asked about their age. It would be easy to conclude that phenomenologically most people are not old, simply because they make this claim. However if we look more closely at the above quote, it contains some interesting subtleties - 'I want to feel old', 'I try to feel young' - which should warn against concluding too quickly that when people claim they don't feel old, they are expressing only an actual physical state. Harry's statement suggests that claims of age are also 
attitudinal, in that they reflect a culturally desirable state - to be youthful, not to be old to which people should aspire. In other words being old is not culturally productive and is rarely admitted to:

Author 2 So there have been some changes.

Graeme Oh yeah physically yeah. There are changes in my body

obviously. And I just can’t walk as far as I could. I used to walk very quickly too but sometimes now I have to really slow down. [...]

Author $2 \quad[\ldots]$ How does that make you feel?

Graeme It makes me feel old.

In this rare admission, we can see physical cues wedged into feelings of age: being old is being less mobile, more fragile (see Graeme’s statement earlier), reported as breathlessness, and in some cases having had a brush with death. Exercise is crucial to bridge the attitudinal and the physical. It helps prolong life, it returns people to the world and the mere fact of being engaged in it is evidence that one is not old because one is doing something about it. Ultimately however it has its own limitations:

Agnes Sometimes I find, I don’t know if you Elizabeth, but your mind up here wants to do it...

Elizabeth wants to do it but you cannae, won’t do it.

Agnes but your body won't allow you.

Elizabeth (laughs) that's how I feel, aye, your body won't allow you.

What is well displayed in this exchange between these two close friends is a balancing act. It is particularly noteworthy that they finish each other's sentences to express a tension between the physical and the attitudinal, giving voice to a more modulated account of ageing where individual volition about fitness hits against something more intractable but to them absolutely real: diminishing bodily potential, with the body as a barrier to improvements in physical competence.

Let us now turn to the instructors’ own understandings of exercise, health and ageing. Health promotion training made them ideally placed to work with older adults. However their accounts of what these older adults had accomplished do not quite match those of the active seniors. This was particularly made visible in relation to ill-health and to how the classes had evolved. 
The instructors had been active in setting up the classes and recruiting older people. They had themselves been recruited to the gym because of their commitment to the promotion of physical activity as a health promotion tool. Therefore they contributed actively to the gym's social mission and were at the vanguard of the development of physical activity as a truly mass movement.

However a few years on, they expressed frustration that the classes had not evolved beyond the early remit that had been set for them (to help people become more active following serious illness). They attributed this primarily to the older adults' attitudes toward exercise. They questioned the active seniors' commitment to exercise as a route to greater fitness and physical competence. Whilst aware that fluctuations in ill-health could hamper regular attendance, they would nevertheless like the class attenders to move beyond illness. Instructor 1 , in the focus group, argues that their approach to exercise is:

Too social - they need to tell you all. ‘Focus on ill health’ like on a heart condition, it's almost like a label they get attached to you know. So they maybe convince themselves they can't do things because they were told in the hospital you know. But that this was two years ago and you have been exercising for two years so you can do a wee bit more, you know (others agree 'yeah' ' $h m$ '). We can see here that a tension emerges between a range of influences: the changing health status of individuals (in large part as a result of exercise), biomedical narratives about exercise, health and ageing, the negotiation of identity around illness and cultural beliefs about age-appropriate behaviour. Whilst recognising this complexity, the instructors personalise the responsibility for failing to progress beyond exercise as illness recovery. This quote contains another element which figured prominently in the instructors' accounts: the 'social' dimension of exercise, as exemplified in this exchange:

Intructor 2 Well they want to go out and meet people. They want to get out of the house.

Instructor $3 \quad[\ldots]$ So it's a good way to do an exercise and carry on out.

Instructor 1 Whereas a student coming along, is quite often already part of a social group [...]. So they come with a group of friends.

$[\ldots]$ 
Instructor 3 Yeah, it's a meeting place. You could say it's like the local community centre. [...]. It’s different from seeing it as a recreation centre, it's physical activity and it's the doing like a multitude of things, or getting a multitude of things from that one.

The 'social' is harnessed to illustrate class users' loose commitment to exercise in and for itself, that is as the pursuit of improved physical competence. They draw a distinction between these gym users and the students, attributing to each group a different construction of the gym: a meeting place and community centre for the old and a recreation centre for the young, the latter reflecting the primary purpose of the gym - to engage in physical activity. Thus old age is put in opposition to standard constructions of exercise and norms of appropriate embodiment and is used to explain the active seniors' apparent reluctance to push themselves.

In other words the instructors would like the older users to transcend the special status they have accorded themselves as survivors ((Frank, 1995)), in remission, and jettison the model of exercise as health and illness management which had initially attracted the users to the gym. It is plausible to infer that the instructors would like the active seniors to adopt a model of exercise which is more in line with the narrative of sporting excellence, associated with striving for excellence in performance which has informed their own trajectory through sport and exercise.

If we look at their own anticipation of ageing, we find that they use techniques which associate increasing age with decreasing athletic ability. They predict an increase in injuries and weakened physicality which will change their engagement with their job:

Author 1 Well is this a job that you see yourself doing, well, for how long? [...] But uhm into your 40s, 50s?

$[\ldots]$

Instructor 2 I can see myself doing Active Senior classes and things like that when I am in my late 40s, early 50s, things like that...

Instructor 1 Maybe go to yoga or something...[...] I think you could teach like Pump and things, couldn't you? 
Instructor 3 Pump, yes, aye you can do Pump until you are 40 plus. Me personally, the way things have worked for me is that my body will pretty much tell me when time is up, or when my enthusiasm just dies a death of it.

Author 1 framed the questioning within a narrow age range which the informants did not transgress, possibly because they could not easily imagine remaining as instructors into late age. We asked them later to imagine what they would do beyond their work years and they all enthusiastically predicted continuing to exercise. However when invited to be more specific they responded as follows:

Author 1 I mean is there something that you could become better at than you are just now as you get older?

Instructor $1 \quad$ Bowls!

Instructors $2 \& 3 \quad$ Bowls, aye.

[...]

Author $1 \quad$ Why bowls?

Instructor 1 (laughs) because I am thinking then you are old. It's also really good fun. What else. I wouldn't see myself getting better at jogging or anything like that.

Instructor 2 Saying that if you put the time in with jogging and all that. I would love to be able to do like a half marathon. Or a marathon. But it's the time you have to invest in the training. Which is not practical.

A difference of opinion emerges within the group which reveals the coexistence of a traditional construction of ageing and an emergent alternative one, according to which the harnessing of time for training could be used to enhance physical competence into advanced age. Arguably however, the traditional discourse of ageing seems to hold sway.

\section{Discussion}

Exercise as a way of promoting health and well-being in later life clearly has merits. As we have seen in the data presented above, the older gym users who attended dedicated classes have enhanced their physical capital over a period of years: they have successfully embedded exercise in their everyday lives, they have improved their 
physical competence, thus staving off immobility and death, they have forged friendships and have garnered a space in a setting normally associated with youthful embodiment. They have also deployed a language consistent with a changed relationship to their bodies, where physical sensations and function are scrutinised to monitor improvements in a bid to manage their own physical ageing. Being embedded in the sub-field of sport and exercise has therefore proven beneficial. However there are subtleties in the encounter between the internalisation of the disposition to exercise and ageing identities which need to be accounted for.

The urge to claim not to be old has been accounted for in the sociological literature as a rejection of social ageing. In this literature, ageing is reported by older people to be a mask (Featherstone, Hepworth, Turner, Hepworth, \& Turner, 1991) which conceals the ageless, that is the real, person beneath. Thus identity is spoilt by ageing and its associations with decrepitude and obsolescence. Older people reassert themselves by claiming they are not old, divorcing themselves from their changing bodies. Since Featherstone and Hepworth (Featherstone \& Hepworth, 1995) first coined and described the Mask of Ageing process, Hepworth (Hepworth, 2004) has modulated it by showing that in some settings older people are more likely to incorporate ageing into their sense of themselves.

In this project we found that ageing is indeed experienced as a liminal and ambiguous process, involving a constant interplay between physical sensations and attitudinal processes. This attitudinal dimension is a cultural response to the undesirability to be seen to be old, with the responsibility to manage ageing successfully (not to act old) lying within individuals, rather than with the structural and cultural processes which enfeeble people as they age. Thus the sub-field of exercise enables older people to deploy the individual disposition and social obligation to improve their health. The fact that this chimes with the postponement of death and deep social isolation obviously makes this deployment much easier to operate.

As we saw above, there appears to be a hiatus between the class users' version of their experiences and the instructors'. The instructors deploy a different narrative of physical competence, in which they give greater weight to improvements in physical competence which they understand within a discourse of exercise as fitness, rather than as health, 
illness recovery and social capital. In health promotion, fitness clearly has overlaps with health. However it is not entirely coincidental with it. The hiatus just alluded to takes place where fitness breaks out of its health boundaries and spills over into sport: the users are happy to attend the classes in their current format, repeating the same routines without ratcheting up exertion levels, whilst the instructors would prefer them to adopt a sport-related model of fitness, based on a culture of the body as athletically competent. This is of course at odds with the users' own interpretations of their bodies' capabilities. Whilst they have largely managed to incorporate a disposition to exercise, their sensitivity to bodily sensations has not diminished (in fact, arguably, people who exercise regularly become more body-oriented) and has only marginally displaced what appears to be a self-imposed threshold of acceptable levels of exertion. They have acquired greater physical capital but this capital is bounded by physical limitations which are either informed by persistent myths about over-exertion or real.

There is a more fundamental limitation to the amount of physical capital acquired by these gym users. The instructors' own accounts of the older people’s use of the gym (invoking the 'social' or the illness label) as well as their anticipation of their own ageing exemplify a persistent association being made between old age, decline and ungainly physicality. Thus it could be argued that the expansion of the sub-field of sport and exercise in which exercise is recast as prescription for health has not fully overturned the low social and cultural position of old people and old age in contemporary society because it continues to rely on a narrow interpretation of sport and exercise, in which alternative physicalities, such as aged physicality, are still denied value.

\section{Conclusion}

We would like to conclude with a reflection on the implications of the above analysis for the provision of exercise to symptomatic older people. We have shown that it is possible for people who had little history of sustained exercise early in the lifecourse and who experienced difficulties associated with secondary ageing and social and cultural isolation, over time to internalise the disposition to become physically active and to work towards improvements in physical competence. The improvements in health and well- 
being which these informants reported appear to corroborate the scientific evidence for a positive association between exercise and the prevention of secondary ageing.

However, as we also noted, there is a tension in the meanings attached to exercise between these exercisers and their instructors.

The ability of this particular group of people to become physically active stems from the presence of welcoming and targeted structures which entice the users to join and remain. The durability of these structures is a key condition for these people to remain physically active. They have not fully adopted a sport-oriented model of physical deployment. When the provision of resources for physical activity is under budgetary pressure, their reluctance to become self-motivated, individual exercisers, engaged in the pursuit of greater fitness and competence, is a threat to the public health project of preventing secondary ageing and promoting well-being via exercise.

Our main recommendation is that gym users and sport centre managers need to develop ways of breaking down barriers in communication to overcome divergent understandings of what constitutes legitimate physical activity. There is clearly more than one model and this needs to be recognised. Most of the respondents in this project were relieved to have overcome premature death and disability. They had also overcome social isolation. However both they and the instructors continued to subscribe to an understanding of ageing as a process of biological decline which fosters low cultural capital.

We would like to question the almost exclusive primacy given to the prevention of illhealth in the marketing of physical exercise to older people. We would like to propose that a more community-oriented approach to physical activity, aimed at fostering enjoyment and happiness derived from the discovery of physicality, and the creation of social ties when these have disappeared, should be given priority over the strict focus on form and health.

The implications for instructors, who largely operate within a fitness and sport model, need to be the object of greater reflection. The issue here is partly one of job satisfaction. We would not recommend that young, highly physically adept athletes should be discouraged from working with older people. This would reinforce the age order and further isolate older people. However the sub-field of fitness and physical activity for 
health needs to be re-shaped, so that all instructors come to view working with different models of exercise as an integral part of their job.

\section{References}

ACSM (2010 Physical Activity and Public health Guidelines

http://www.acsm.org/AM/Template.cfm?Section=Home_Page\&TEMPLATE=CM/HTM

LDisplay.cfm\&CONTENTID=7764 Accessed 05/09/2010

Armstrong, L. (2001). It's not about the bike: My journey back to life. London: Random House.

Armstrong, L. (2004). Every second counts. London: Random House.

Asikainen, T. -., Kukkonen-Harjula, K., \& Miilunpalo, S. (2004). Exercise for health for early postmenopausal women: A systematic review of randomised controlled trials. Sports Medicine, 34(11), 753-778.

Balde, A., Figueras, J., Hawking, D. A., \& Miller, J. R. (2003). Physician advice to the elderly about physical activity. Journal of Aging and Physical Activity, 11, 90-97.

Beitz, R., \& Doeren, M. (2004). Physical activity and postmenopausal health. Journal of the British Menopause Society, 10(2), 70-74.

Bourdieu, P. (1979). La distinction: Critique sociale du jugement. Paris: Les Editions de Minuit.

Bourdieu, P. (1987). Choses dites. Paris: Editions de Minuit. 
Byberg, L., Melhus, H., Gedeborg, R., Sundstrom, J., Ahlbom, A., Zethelius, B., et al. (2009). Total mortality after changes in leisure time physical activity in 50 year old men: 35 year follow-up of population based cohort. BMJ, 338(mar05_2), b688.

Cress, M. E., Buchner, D. M., Questad, K. A., Esselman, P. C., deLateur, B. J., \& Schwartz, R. S. (1999). Exercise: Effects on physical functional performance in independent older adults. Journal of Gerontology: Biological Sciences and Medical Sciences, 54A(5), 242-248.

DeSouza, C. A., Stevenson, E. T., Davy, K. P., Parker Jones, P., \& Seals, D. R. (1997). Plasma fibrinogen levels in healthy postmenopausal women: Physical activity and hormone replacement status. Journal of Gerontology: Biological Sciences and Medical Sciences, 52A(5), M294-M298.

Featherstone, M., \& Hepworth, M. (1995). The mask of ageing and the postmodern lifecourse. In M. Featherstone, M. Hepworth \& B. S. Turner (Eds.), The body: Social process and cultural theory (pp. 371-389). London: Sage.

Featherstone, M., Hepworth, M., Turner, B. S., Hepworth, M., \& Turner, B. S. (1991). The body: Social process and cultural theory. London: SageFeatherstone, M.

Ferrara, N., Pisanelli, P., Voza, M., Abete, D., Leosco, D., Filippelli, A., et al. (2002). The aging heart and exercise training. Archives of Gerontology and Geriatrics, Suppl. 8, 145-156. 
Frank, A. W. (1995). The wounded storyteller: Body, illness, and ethics. Chicago: Chicago University Press.

Gullette, M. M. (2004). Aged by culture. Chicago: University of Chicago Press.

Hepworth, M. (2004). Embodied agency, decline and the masks of aging. In E. Tulle (Ed.), Old age and agency (pp. 125-135). Hauppauge, NY: Nova Science.

Hughes, A. R., Mutrie, N., \& MacIntyre, P. (2007). Effect of an exercise consultation on maintenance of physical activity after completion of phase III exercise-based cardiac rehabilitation. European Journal of Cardiovascular Prevention and Rehabilitation, $14,114-121$.

Hunter, G. R., McCarthy, J. P., \& Bamman, M. M. (2004). Effects of resistance training on older adults. Sports Medicine, 34(5), 329-348.

Kunstler, R., \& Stavola Daly, F. (2010). Therapeutic recreation leadership and programming. Champaign Ill.: Human Kinetics.

Nelson, M. E., Rejeski, W. J., Blair, S. N., Duncan, P. W., Judge, J. O., King, A. C., et al. (2007). Physical activity and public health in older adults: Recommendation from the american college of sports medicine and the american heart association. Medicine \& Science in Sports and Exercise, 39(8), 1435-1445.

Phoenix, C., Smith, B., \& Sparkes, A. C. (2010). Narrative analysis in aging studies: A typology for consideration. Journal of Aging Studies, 24(1), 1-11. 
Sassatelli, R. (2010). Fitness culture. London: Palgrave.

Scottish Executive. (2005). The scottish health survey 2003: Summary of key findings. Edinburgh: Crown Copyright.

Shephard, R. J. (1997). Aging, physical activity, and health. Champaign, IL.: Human Kinetics.

Silverman, D. (2005). Doing qualitative research: A practical handbook. London: Sage.

Tulle, E. 2008 Ageing, the body and social change : running in later life, Basingstoke: Palgrave.

Williamson, D. L., \& Kirwan, J. P. (1997). A single bout of concentric resistance exercise increases basal metabolic rate 48 hours after exercise in healthy 59-77 year-old men. Journal of Gerontology: Biological Sciences and Medical Sciences, 52A(6), M352M355.

WHO (2010) Global Strategy on Diet, Physical Activity and Health http://www.who.int/dietphysicalactivity/factsheet_recommendations/en/index.html Accessed 05/09/2010 